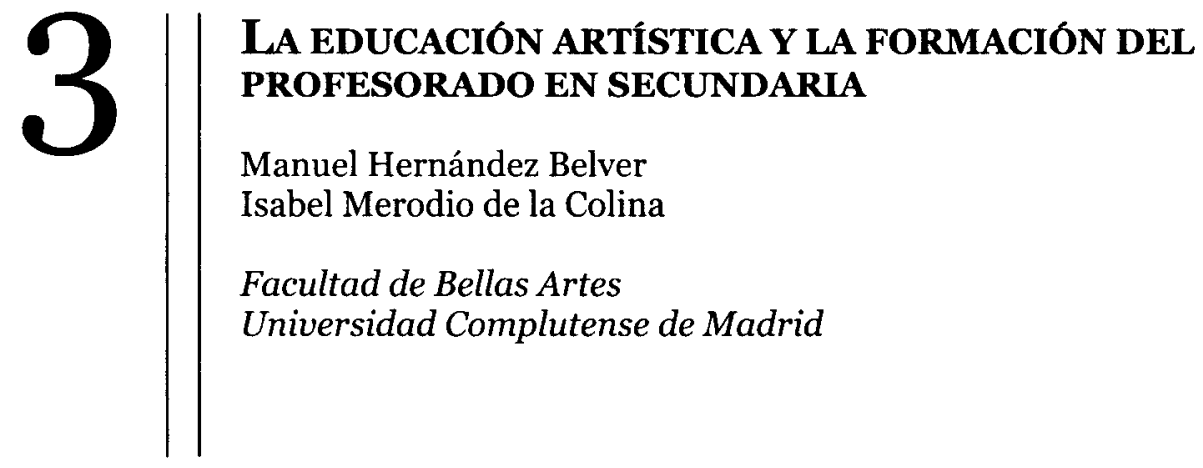

La educación artística, como cualquier disciplina, ha conocido, a lo largo de su existencia, diferentes condiciones. En los tiempos actuales, los cambios son tan rápidos que las continuas reformas apenas pueden no ya preverlos, sino siquiera reflejar tales cambios cuando el proceso de dichas reformas termina. Sin embargo, cómo queden reflejados esos cambios y cómo puedan hacer frente a los retos del futuro, es un factor decisivo para que una reforma pueda considerarse un éxito, o como poco, no sea un fracaso.

En todo proceso educativo, como se sabe, son varios los factores implicados. Y se suele incidir, con razón, en la formación del futuro profesorado, por ser ésta una de las claves del éxito de cualquier reforma. Un profesorado bien formado, motivado y vocacional puede llevar a cabo casi cualquier propuesta, o como poco, proporcionar entidad a la disciplina y hacerla valorar por los alumnos y la sociedad en su conjunto.

Esto, que parece tan fácil, no lo es tanto a la hora de llevarlo a la práctica. No vamos a entrar en las diversas dificultades que atraviesa el profesorado en general y el de secundaria en particular, porque excedería ampliamente el espacio y el objeto de este artículo. Únicamente nos vamos a detener en considerar uno de los 
factores de este proceso, el de la formación del profesorado de secundaria en educación artística, a raíz de la última y frustrada reforma del Curso de Aptitud Pedagógica, el conocido y ya famoso CAP25.

\section{LA FORMACIÓN INICLAL DEL PROFESORADO DE SECUNDARIA EN EDUCACIÓN ARTÍSTICA}

Este profesorado, como sabemos, procede en su inmensa mayoría de las $\mathrm{Fa}$ cultades de Bellas Artes, en cuyos planes de estudios se contempla, aunque en proporciones excesivamente desventajosas con respecto a otras materias, una formación en didáctica específica para aquellos alumnos que en el futuro quieran dedicarse a la docencia. Dichas materias, correspondientes al área de Didáctica de la Expresión Plástica e impartidas desde los Departamentos correspondientes en dichas Facultades, tienen una presencia diversa en cada Centro, debido en parte a su carácter de optativas y también a la diferente presencia de esos Departamentos en las diferentes Facultades, tanto en número de créditos, como de asignaturas o de profesorado encargado de impartirlas. Por ello nos referiremos en este trabajo al caso de la Facultad de Bellas Artes de Madrid, que puede servir como modelo para las propuestas que aquí se plantearán.

Esa presencia irregular ha supuesto una primera dificultad para la coordinación de esas enseñanzas, sobre todo desde la primera renovación de los planes de estudio de estas Facultades, a principios de los años 90. Paradójicamente, mientras en la reforma de secundaria se creaba el Bachillerato artístico, en Bellas Artes se reducían las materias de educación artística, en algunos casos hasta casi la desaparición. Esta situación, unida a la permanencia del CAP invariable durante todos estos años, ha hecho que la formación del profesorado de secundaria haya estado bastante desvinculada de los Centros de referencia, como no lo había sido desde hacía mucho tiempo. Recuérdese, por ejemplo, que después de muchos años los alumnos de las antiguas Escuelas de Bellas Artes consiguieron que su título fuera reconocido como de "profesor de dibujo", y consecuentemente, se reflejó en los planes de estudio de la época una formación específica para ello.

Ha sido en etapas más recientes cuando se ha vuelto a reconocer por todas las partes implicadas la importancia de la formación pedagógica en estos estudios. A ello ha contribuido, entre otras cosas, su consolidación en el ámbito universitario, el avance de la investigación en este campo o el reconocimiento de unas salidas profesionales que suponen un alto porcentaje de los titulados.

Por ejemplo, en el informe Estudio sobre la inserción laboral de los titulados en Bellas Artes, realizado por la Universidad Complutense, se recoge en sus conclusiones, entre otros datos, que uno de los sectores donde se sitúa la mayor parte de la actividad laboral de estos titulados es la relativa a la docencia en Be-

\footnotetext{
${ }^{25}$ REAL DECRETO 850/1993 de 4 de junio.
} 
llas Artes, que se acerca al 30\% sólo en los tres años siguientes al de la licenciatura. $\mathrm{Si}$ a esto se añade el porcentaje de titulados que continúa el tercer ciclo y/o que preparan oposiciones, este porcentaje se eleva considerablemente en los años sucesivos ${ }^{26}$. Esta nueva sensibilización contribuirá, sin duda, a que en la nueva adaptación de los planes de estudios a la Convergencia europea, estos factores se vean reflejados, y se supere por fin la etapa de precariedad que tanto ha perjudicado a la formación de nuestros alumnos.

\section{ANÁLISIS DEL ESTADO DE LA CUESTIÓN DE LA FORMACIÓN DEL PROFESORADO EN EDUCACIÓN ARTISTICA}

En todo este proceso, los cursos de formación del profesorado impartidos en los ICEs han estado presentes de una manera marginal. Los sucesivos planes de estudios de las Facultades no pudieron contemplar una mayor coordinación con este tipo de estudios, que en la mayoría de los casos resultaban decepcionantes para los alumnos, cuando no una pérdida de tiempo y de dinero. Al ser también diferentes en las respectivas universidades, había alumnos que preferían cursarlos en otras, y en pocas semanas liquidaban un trámite que en sus Centros de origen podían suponerles varios meses o cursos académicos. Todo ello debido, fundamentalmente, a la falta de motivación por estos cursos, su poca utilidad, la escasez de medios a disposición, la masificación, etc. A ello añadiríamos, en nuestro caso, la desubicación de estos alumnos, que en estudios de este tipo es más problemática.

Antes de analizar lu situación actual, veamos los antecedentes de estos estudios. La organización de estos cursos tiene su origen en el Real Decreto 2476/1965 de 22 de julio, de creación de la Escuela de Formación del Profesorado de Grado Medio. Esta Escuela dependía del Ministerio de Educación Nacional, y estaba bajo la superior dirección de un Consejo presidido por el ministro e integrado por los directores generales. A ella se encomendó la capacitación técnicopedagógica de los aspirantes al profesorado en Centros de Grado Medio, así como el perfeccionamiento de los profesores de esos mismos Centros. Sus fines eran:

a) Organizar y desarrollar las actividades convenientes para la formación de los aspirantes al profesorado y el perfeccionamiento de los profesores de Enseñanza Media, Enseñanza Media y Profesional, Escuelas de Magisterio, Formación Industrial, Escuelas de Comercio, Escuelas Técnicas de Grado Medio y otros Centros de este Grado para los que así se determinara por Orden ministerial.

\footnotetext{
${ }^{26}$ Estudio sobre la inserción laboral de los titulados en Bellas Artes. (2002). Madrid: Universidad Complutense.
} 
b) Promover, dirigir y coordinar en los diversos Centros docentes las actividades encaminadas a la formación pedagógica de los alumnos de la Escuela.

c) Capacitar al profesorado para las demás actividades de carácter formativo y para el desempeño de funciones directivas.

d) Informar a las autoridades del Ministerio sobre las mejoras que conviniera introducir en materia de sus competencias ${ }^{27}$.

Desde 1965, hasta llegar a la instauración del Curso de Actualización Pedagógica (CAP), estos estudios sufrieron sucesivas modificaciones de acuerdo con los cambios de la sociedad. En la actualidad, la reforma de estos cursos formativos, vista como necesaria por todas las partes implicadas, se ha vista aplazada una y otra vez por diversas circunstancias.

Ya el Real Decreto 1692/1995 de 20 de octubre recogía la exigencia de la Ley Orgánica 1/1990, de 3 de octubre, de Ordenación General del Sistema Educativo (LOGSE), de estar en posesión de un título profesional de especialización didáctica, obtenido mediante la realización de un Curso de Cualificación Pedagógica (CCP), para impartir las enseñanzas de la educación secundaria obligatoria, del bachillerato y de la formación profesional específica ${ }^{28}$. Asimismo, en la disposición adicional undécima, la Ley plantea idéntica exigencia para el ingreso en el cuerpo de Profesores de Enseñanza Secundaria y en el cuerpo de Profesores Técnicos de Formación Profesional, y en la disposición adicional cuarta exceptúa de esta exigencia a los maestros y a los licenciados en pedagogía.

Además de encomendar al Gobierno la regulación del acceso a dicho curso, así como del carácter y efecto de los correspondientes títulos, establecía para él una duración mínima de un año, y la inclusión de prácticas docentes. En la disposición adicional séptima del Real Decreto 986/1991, de 14 de junio, por el que se aprobaba el calendario de aplicación de la nueva ordenación del sistema educativo, modificado y completado por el Real Decreto 1487/1994, de 1 de julio, se ponía como límite para la aplicación de este título el curso 1996-199729.

\section{El TÍTULO DE ESPECIALIZACIÓN DIDÁCTICA (TED) EN LA L.O.G.S.E.}

En su declaración de intenciones, el Real Decreto mencionado resalta la importancia del ya denominado Título de Especialización Didáctica (TED), destacando su valor de acreditación para ejercer la docencia, es decir, su valor profe-

\footnotetext{
${ }^{27}$ REAL DECRETO 2476/1965 de 22 de julio, de creación de la Escuela de Formación del Profesorado de Grado Medio (BOE 10-1X-1965; BM 27-IX-1965).

${ }^{28}$ REAL DECRETO 1692/1995 de 20 de octubre. LEY ORGANICA 1/1990, de 3 de octubre, de Ordenación General del Sistema Educativo (LOGSE).

${ }^{29}$ REAL DECRETO 986/1991, de 14 de junio (disposición adicional séptima). REAL DECRETO 1487/1994, de 1 de julio.
} 
sional, a quienes lo posean. De ahí la conveniencia de vincular las enseñanzas que conformen dicho título tanto a Universidades, como a Institutos de Secundaria y los sectores productivos. Se disponía, por tanto, su obligatoriedad para poder impartir la docencia en secundaria a nivel nacional, así como los requisitos mínimos de titulación para su obtención, que eran los habituales para los postgrados.

El plan de estudios fijaba una carga lectiva entre 60 y 75 créditos de equivalencia actual (10 horas), divididos en dos bloques de enseñanzas: uno teóricopráctico y otro de prácticas docentes. El primer bloque, cuya carga lectiva serían 40 créditos como mínimo, estaría formado por materias obligatorias y optativas. Las primeras a su vez serían generales (aspectos sociológicos, pedagógicos y psicológicos) y específicas (aspectos didácticos correspondientes a las especialidades), mientras que las optativas servirían para completar la formación en las materias de las especialidades, y no podrían superar el 20 por ciento del total del bloque.

El bloque práctico incluía prácticas docentes tutorizadas en las áreas de especialización correspondientes, y su carga lectiva serían 15 créditos, de los cuales al menos 10 se destinarían a practicar la docencia tutorizada en centros de educación secundaria y el resto a la preparación, análisis, reflexión y valoración de las prácticas docentes realizadas. A estos efectos, se subrayaba la importancia de la coordinación entre ambos bloques y el profesorado encargado de ellos, tanto los de las disciplinas como los tutores de los alumnos en prácticas.

Por último, se encargaba a las Administraciones educativas la puesta en práctica de esta reforma a lo largo del curso 1995-96, para que estuviera plenamente operativo en el siguiente curso académico. Se establecía una revisión y posible modificación durante el curso 1998-99, para que por fin el título de especialización didáctica estuviera plenamente implantado en el siguiente curso 19992000 .

Esta situación prevista fue alterada por el Real Decreto 173/1998, de 16 de febrero, que modificó, entre otras, la disposición adicional séptima del Real Decreto 986/1991, de 14 de junio, por el que se aprobaba el calendario de aplicación de la nueva ordenación del sistema educativo. Además se estableció, por el Real Decreto 321/200o de 3 de marzo, que la generalización de las enseñanzas conducentes al título de Especialización Didáctica no se haría hasta el curso 2002-2003, así como que las enseñanzas conducentes a la obtención de los certificados de aptitud pedagógica expedidos por los Institutos de Ciencias de la Educación podrían seguir organizándose hasta el curso 2001-200230. De esta forma, el TED no se hacía obligatorio hasta dicho curso 2002-2003.

\footnotetext{
${ }^{30}$ REAL DECRETO 173/1998, de 16 de febrero, REAL DECRETO 321/2000 de 3 de marzo
} 


\section{EL TÍTULO DE ESPECIALIZACIÓN DIDÁCTICA (TED) EN LA L.O.C.E.}

La Ley Orgánica 10/2002, de 23 de diciembre, de Calidad de la Educación, recogía de nuevo esta necesidad y la hacía suya, no sólo en la necesidad de potenciar y desarrollar la formación del profesorado, sino especificando la necesidad del TED en su articulado. Así, en el artículo 58, vuelve a incidir en la necesidad de poseer este título para impartir la docencia en Secundaria, en Formación Profesional de grado superior y en las enseñanzas de régimen especial ${ }^{31}$, necesidad que se remarca en la disposición adicional duodécima, donde se hace referencia a ellas de nuevo.

El desarrollo normativo de esta titulación se concretó en el Real Decreto 118/2004 de 23 de enero, por el que se regulaba el título de Especialización Didáctica. Tomando como base el antiguo Real Decreto 1692/1995 de 20 de octubre, en sus preliminares se recuerda la conveniencia de atraer a los estudiantes hacia la profesión docente, y la necesidad de fomentar la configuración del perfil docente en el alumnado durante los estudios de su titulación universitaria ${ }^{32}$, tratando de que esto se pueda traducir en una especialización concreta dentro de las directrices de la Convergencia europea.

Las características de este título se pueden resumir en las siguientes:

1. Destacaba la necesidad de potenciar el perfil docente en el alumnado, y lo hace vinculándolo a la titulación universitaria. Es decir, la especialización docente no es una opción posterior a la titulación, sino que se plantea ya desde y en la propia Facultad, facilitando su inclusión en la estructura de los planes de estudios.

2. Delegaba en las Administraciones educativas la elaboración de los planes de estudios, cuyo tiempo total no debía superar los dos cursos académicos, de los cuales el de prácticas debería ser como mínimo de tres meses. No obstante, facilitaba la realización de convenios entre estas Administraciones y las Universidades para organizar y desarrollar los períodos académicos y de prácticas.

3. En línea con lo planteado ya en el antiguo R.D., el plan de estudios del período académico se componía también de un mínimo de 60 créditos (60'5 en realidad), de los cuales 12 correspondían al período de prácticas y 48' 5 al académico. Las materias de éste se dividían a su vez en comunes a todas las especialidades (áreas de pedagogía, psicología y sociología, 25 '5 créditos), materias específicas de cada especialidad (12 créditos) y materias complementarias u optativas ( 11 créditos).

\footnotetext{
${ }^{31}$ LEY ORGÁNICA 10/2002, de 23 de diciembre, de Calidad de la Educación

${ }^{32}$ REAL DECRETO (RD) $118 / 2004$ de 23 de enero. (B.O.E. 4 de febrero de 2004).
} 
4. El período de prácticas se desarrollaría en los centros docentes correspondientes a las enseñanzas respectivas, y sería tutelado por una comisión calificadora nombrada al efecto por las Administraciones educativas, integrada por profesorado funcionario. Incluiría un curso de formación de 12 créditos, y la realización de un proyecto didáctico.

\section{PROPUESTA DE LA UNIVERSIDAD COMPLUTENSE PARA LA FORMACIÓN DEL PROFESORADO DE SE- CUNDARIA}

Este Real Decreto suponía, a pesar de las críticas que pudo suscitar, la culminación de un período de precariedad y provisionalidad que duraba ya casi 15 años. En todo este tiempo, los alumnos que se sentían atraídos por la carrera docente no encontraban más que un sucedáneo, hecho con más voluntad que medios, fuera de sus Centros de estudios y con posterioridad a la finalización de la licenciatura. Durante todo este tiempo, la formación de los futuros docentes estuvo a cargo de los ICEs y los contenidos que allí se impartían eran fundamentalmente de las áreas comunes, mientras a las específicas se les reservaba un papel mucho menor. Por ello, una normativa así fue mayoritariamente bienvenida por todas las áreas específicas afectadas, y en especial aquellas, como la nuestra, que también tienen presencia en las Facultades respectivas. Era una oportunidad para conseguir unificar por fin nuestras enseñanzas, todavía minoritarias, con la formación didáctica integral de nuestros alumnos.

Con este fin todos los Departamentos afectados, con la coordinación del ICE de la Complutense, preparamos una propuesta coherente de cara al inicio del nuevo Curso de Especialización Didáctica (TED) para el Profesorado de Educación Artística de Secundaria. Junto a nuestra Universidad estaban también las demás Universidades públicas madrileñas, a fin de presentar un proyecto común a la Administración educativa correspondiente, en este caso a la Comunidad Autónoma de Madrid (CAM).

El proyecto presentado por la UCM partía de una serie de consideraciones legales preliminares, como eran la imposibilidad legal de prolongar el CAP el siguiente curso académico (2004-2005) y la responsabilidad de la CAM en el desarrollo y organización del TED. Se hacía una serie de propuestas organizativas para poder disponer del TED en ese curso, como eran:

- $\quad$ Acuerdo entre las Universidades públicas madrileñas para el reconocimiento común automático de los créditos correspondientes a las materias comunes, complementarias u optativas cursadas en cualquiera de ellas, debido a que algunas de ellas carecen de departamentos para impartir las materias comunes y algunas de las específicas, el reparto de áreas en función de los recursos y características de cada universidad, asignación de algunas minoritarias a una sola de las universidades, etc. 
- Previsiones de infraestructuras, profesorado y costes económicos, previsiones de alumnado, propuestas de grupos para cada materia, etc.

Por nuestra parte, y de acuerdo con estas previsiones, el Departamento de Didáctica de la facultad de Bellas Artes elaboró también una propuesta, teniendo en cuenta además las enseñanzas especiales a que alude la ley Orgánica y el RD y cuya implementación parece confusa. Dicha propuesta, lógicamente, concretaba más el desarrollo de las materias de nuestra área, encajándolas en el plan de estudios vigente y con las asignaturas actuales, en previsión de su desarrollo posterior en la próxima reforma de dicho plan, de acuerdo con los planes de la Convergencia europea.

\section{ANÁLISIS DE LA SITUACIÓN ACTUAL}

Sin embargo, en pleno proceso de preparación, el Real Decreto 1318/2004 de 28 de mayo modificaba de nuevo el anterior $\mathrm{RD} 827 / 2003$ de 27 de junio, paralizando la entrada en vigor de algunas de las medidas contempladas en éste, y en concreto, el TED. Así, en su artículo único, establece el aplazamiento hasta el curso 2006-2007 la aplicación de las medidas previstas para el curso 2004$2005^{33}$ para, entre otros artículos y disposiciones, la disposición adicional segunda de dicho Real Decreto, el referido a la puesta en marcha del Título de Especialización Didáctica.

Es así que el consabido CAP es necesariamente resucitado de nuevo y, como ave Fénix, vuelve a marcar los destinos de nuestros alumnos (y los nuestros) durante otros dos cursos al menos. Frente a la adversidad que puede suponer esta situación, se impone el ser prácticos, y aprovechar la circunstancia para, valiéndonos de la experiencia pasada, enmendar errores y utilizar este tiempo para preparar, aparcando intereses de distinto tipo, unas propuestas que mejoren las anteriores, confiando en que el Ministerio y las Administraciones educativas nos ofrezcan por fin las herramientas para proporcionar a los alumnos el marco adecuado para su formación como docentes.

\section{PROPUESTA PARA LA FORMACIÓN DEL PROFESO- RADO DE EDUCACIÓN ARTÍSTICA EN SECUNDARIA}

En esta previsión, nuestras propuestas para el desarrollo del proyecto del nuevo CAP, en línea con lo expuesto anteriormente para el TED, son las siguientes:

1. Siempre que se pueda, el período académico debería impartirse en los Centros respectivos, lo que redundaría en:

\footnotetext{
${ }^{33}$ REAL DECRETO $1318 / 2004$ de 28 de mayo, REAL DECRETO $827 / 2003$ de 27 de junio.
} 
a) mejora para el alumnado, que lo podría cursar con facilidad en su propia Facultad.

b) mejora del contenido didáctico específico, que estaría siempre actualizado.

En cualquier caso, sí debe ser incuestionable que esto afecte por lo menos a las materias específicas y las complementarias u optativas. Siempre que se disponga de espacios, como es nuestro caso y el de otros muchos Centros, es más fácil y operativo que se desplace el profesorado y no todo el alumnado.

2. El profesorado encargado del desarrollo y aplicación del período, tanto académico como práctico, debe ser el de los Departamentos de las áreas específicas, y en especial en aquellos centros donde estos están presentes como consecuencia de su necesidad, que son los deberían coordinar todo el proceso. En todo caso, siempre debería participar de alguna forma el profesorado de los Centros respectivos.

3. Esta coordinación debería extenderse al período de prácticas, en las que debe contarse, obviamente, con el Profesorado de Secundaria y el Profesorado de Artes Plásticas y Diseño para las labores tutoriales.

4. La importancia de mantener las didácticas específicas de las Bellas Artes dentro de su Facultad es especialmente importante, si se quiere mantener un rigor y, a la vez, una actualización artística permanente. Precisamente esa conexión entre universidad y sociedad es uno de los fines importantes de la actual educación.

En este sentido, la propuesta que presentamos, basada en los planteamientos del RD 118/2004 de 23 de enero, que desarrollaba el TED, para el área de Didáctica de la Expresión Plástica en las Facultades de Bellas Artes es la siguiente: 


\section{TÍTULO DE ESPECIALIZACIÓN DIDÁCTICA}

DESARROLLO DEL ANEXO II

B. MATERIAS ESPECÍFICAS. (12 créditos mínimo)

COMÚN PARA PROFESORES DE SECUNDARIA Y PROFESORES DE ARTES PLÁSTICAS Y DISEÑO

\section{Cuadro N. ${ }^{\circ}$ 1.1. Título de Especialización Didáctica}

\begin{tabular}{|c|c|c|c|c|c|}
\hline \multirow[t]{2}{*}{ Denominación } & \multirow[t]{2}{*}{ Plan de estudios } & \multicolumn{3}{|c|}{ Créditos anuales } & \multirow{2}{*}{$\begin{array}{l}\text { Vinculación a } \\
\text { áreas de } \\
\text { conocimiento }\end{array}$} \\
\hline & & Totales & Teóricos & Prácticos & \\
\hline \multirow[t]{2}{*}{$\begin{array}{l}\text { B.1. Didáctica } \\
\text { de las Artes } \\
\text { Plásticas }\end{array}$} & $\begin{array}{l}\text { Didáctica de la edu- } \\
\text { cación artístico plás- } \\
\text { tica: El currículo de las } \\
\text { asignaturas de la educa- } \\
\text { ción artístico plástica y } \\
\text { sus campos científicos: } \\
\text { aspectos conceptuales y } \\
\text { prácticos para su elabo- } \\
\text { ración y aplicación en } \\
\text { situaciones de aprendi- } \\
\text { zaje. Selección, ordena- } \\
\text { ción y codificación del } \\
\text { conocimiento. La eva- } \\
\text { luación. }\end{array}$ & 4 & 2 & 2 & \multirow[t]{2}{*}{$\begin{array}{l}\text { Área artística } \\
\mathrm{n}^{\circ} 4: \text { Artes } \\
\text { Plásticas } \\
\text { Didáctica de } \\
\text { la Expresión } \\
\text { Plástica }\end{array}$} \\
\hline & $\begin{array}{l}\text { La unidad didáctica } \\
\text { en las Artes Plásti- } \\
\text { cas. Diseño de unida- } \\
\text { des didácticas para la } \\
\text { educación } \text { artístico } \\
\text { plástica. La unidad } \\
\text { didáctica en el aula. } \\
\text { Metodología, estrate- } \\
\text { gias y recursos. Inter- } \\
\text { disciplinariedad. }\end{array}$ & 4 & 2 & 2 & \\
\hline
\end{tabular}




\section{Cuadro N. ' 1.2. Título de Especialización Didáctica}

\begin{tabular}{|c|c|c|c|c|c|}
\hline \multirow[t]{2}{*}{ Denominación } & \multirow[t]{2}{*}{ Plan de estudios } & \multicolumn{3}{|c|}{ Créditos anuales } & \multirow{2}{*}{$\begin{array}{l}\text { Vinculación a } \\
\text { áreas de } \\
\text { conocimiento }\end{array}$} \\
\hline & & Totales & Teóricos & Prácticos & \\
\hline \multirow[t]{2}{*}{$\begin{array}{l}\text { B.1. Didáctica } \\
\text { de las Artes } \\
\text { Plásticas }\end{array}$} & $\begin{array}{l}\text { Investigación e in- } \\
\text { novación en las ar- } \\
\text { tes plásticas: Investi- } \\
\text { gación didáctica de las } \\
\text { artes plásticas. Innova- } \\
\text { ción y experimentación } \\
\text { didáctica. Aplicaciones } \\
\text { multimedia. }\end{array}$ & 4 & 2 & 2 & \\
\hline & $\begin{array}{l}\text { Bases didácticas de } \\
\text { las Artes Visuales: } \\
\text { Enfoques que desde } \\
\text { distintas ramas de las } \\
\text { Ciencias Sociales con- } \\
\text { dicionan los fenómenos } \\
\text { artísticos, así como sus } \\
\text { aplicaciones a la ense- } \\
\text { ñanza de las artes. }\end{array}$ & 4 & 3 & 1 & \\
\hline
\end{tabular}


C. MATERIAS COMPLEMENTARIAS o, EN SU CASO, OPTATIVAS. (11 créditos mínimo).

PARA FUTUROS PROFESORES DE EDUCACIÓN SECUNDARIA

\section{Cuadro N. " 1.3. Título de Especialización Didáctica}

\begin{tabular}{|c|c|c|c|c|c|}
\hline \multirow[t]{2}{*}{ Denominación } & \multirow[t]{2}{*}{ Plan de estudios } & \multicolumn{3}{|c|}{ Créditos anuales } & \multirow{2}{*}{$\begin{array}{l}\text { Vinculación a } \\
\text { áreas de } \\
\text { conocimiento }\end{array}$} \\
\hline & & Totales & Teóricos & Prácticos & \\
\hline \multirow[t]{2}{*}{$\begin{array}{l}\text { C.1. Materias } \\
\text { complemen- } \\
\text { tarias }\end{array}$} & $\begin{array}{l}\text { Creatividad y Edu- } \\
\text { cación Artistica: } \\
\text { Estudio de los métodos } \\
\text { y procesos de la Creati- } \\
\text { vidad dentro del con- } \\
\text { texto de la Educación } \\
\text { artística }\end{array}$ & 4 & 2 & 2 & \multirow[t]{2}{*}{$\begin{array}{l}\text { Área de Espe- } \\
\text { cialización } \\
\text { Didáctica } n^{\circ} 4 \\
\text { Didáctica de } \\
\text { la Expresión } \\
\text { Plástica. }\end{array}$} \\
\hline & $\begin{array}{l}\text { Artista Sociedad y } \\
\text { Educación: La For- } \\
\text { mación del Artista, su } \\
\text { relación con la sociedad } \\
\text { y el espectador de ese } \\
\text { momento, reflejo de los } \\
\text { diferentes factores cul- } \\
\text { turales, sociales, políti- } \\
\text { cos, económicos, etc. en } \\
\text { el desarrollo de la edu- } \\
\text { cación artística. }\end{array}$ & 4 & 2 & 2 & \\
\hline
\end{tabular}




\section{Cuadro N. ${ }^{\circ}$ 1.4. Título de Especialización Didáctica}

\begin{tabular}{|c|c|c|c|c|c|}
\hline \multirow[t]{2}{*}{ Denominación } & \multirow[t]{2}{*}{ Plan de estudios } & \multicolumn{3}{|c|}{ Créditos anuales } & \multirow{2}{*}{$\begin{array}{l}\text { Vinculación a } \\
\text { áreas de } \\
\text { conocimiento }\end{array}$} \\
\hline & & Totales & Teóricos & Prácticos & \\
\hline $\begin{array}{l}\text { C.1. Materias } \\
\text { complemen- } \\
\text { tarias }\end{array}$ & $\begin{array}{l}\text { Asignaturas del Ba- } \\
\text { chillerato de Artes } \\
\text { Plásticas: Dibujo Ar- } \\
\text { tístico, Dibujo Técnico, } \\
\text { Fundamentos de Dise- } \\
\text { ño, Imagen, Técnicas } \\
\text { de Expresión Gráfico } \\
\text { Plástica, Volumen: El } \\
\text { currículo de las asigna- } \\
\text { turas y sus campos } \\
\text { científicos: aspectos } \\
\text { conceptuales y prácti- } \\
\text { cos para su elaboración } \\
\text { y aplicación a situacio- } \\
\text { nes de aprendizaje. La } \\
\text { evaluación. Diseño de } \\
\text { unidades didácticas. }\end{array}$ & 4 & 2 & 2 & \\
\hline $\begin{array}{l}\text { C.2. Materias } \\
\text { Optativas }\end{array}$ & $\begin{array}{l}\text { Asignaturas optati- } \\
\text { vas del Bachillerato } \\
\text { de Artes Plásticas: } \\
\text { Ampliación de sistemas } \\
\text { de Representación, } \\
\text { Volumen II, Talleres } \\
\text { (Textil, Gráfico, de } \\
\text { Estampación, Talla en } \\
\text { Piedra, Talla en Made- } \\
\text { ra, Cuero, Dorado y } \\
\text { Policromía, Fotografia, } \\
\text { Forja, Esmalte, etc.): El } \\
\text { currículo de las asigna- } \\
\text { turas y sus campos } \\
\text { científicos: aspectos } \\
\text { conceptuales y prácti- } \\
\text { cos para su elaboración } \\
\text { y aplicación a situacio- } \\
\text { nes de aprendizaje. La } \\
\text { Evaluación. Diseño de } \\
\text { Unidades Didácticas. }\end{array}$ & 4 & 2 & 2 & \\
\hline
\end{tabular}


C. MATERIAS COMPLEMENTARIAS O, EN SU CASO, OPTATIVAS. (11 créditos mínimo)

PARA FUTUROS PROFESORES DE ARTES PLÁSTICAS Y DISEÑO

\section{Cuadro N. ' 1.5. 'Título de Especialización Didáctica}

\begin{tabular}{|c|c|c|c|c|c|}
\hline \multirow[t]{2}{*}{ Denominación } & \multirow[t]{2}{*}{ Plan de estudios } & \multicolumn{3}{|c|}{ Créditos anuales } & \multirow{2}{*}{$\begin{array}{l}\text { Vinculación a } \\
\text { áreas de } \\
\text { conocimiento }\end{array}$} \\
\hline & & Totales & Teóricos & Prácticos & \\
\hline \multirow{2}{*}{$\begin{array}{l}\text { C.1. Materias } \\
\text { Complemen- } \\
\text { tarias: } \\
\text { (Aplicadas en } \\
\text { cada caso a las } \\
\text { diferentes es- } \\
\text { pecialidades } \\
\text { propias de los } \\
\text { estudios de } \\
\text { Artes Plásticas } \\
\text { y Diseño) }\end{array}$} & $\begin{array}{l}\text { Creatividad y Edu- } \\
\text { cación Artística: } \\
\text { Estudio de los métodos } \\
\text { y procesos de la Creati- } \\
\text { vidad dentro del con- } \\
\text { texto de la Educación } \\
\text { artística. }\end{array}$ & 4 & 2 & 2 & \multirow{2}{*}{$\begin{array}{l}\text { Área } 18 \text { de } \\
\text { Especializa- } \\
\text { ción Didácti- } \\
\text { ca (ver obser- } \\
\text { vación en la } \\
\text { p.60) } \\
\text { Didáctica de } \\
\text { la Expresión } \\
\text { Plástica }\end{array}$} \\
\hline & $\begin{array}{l}\text { Artista Sociedad y } \\
\text { Educación: La For- } \\
\text { mación del Artista, su } \\
\text { relación con la sociedad } \\
\text { y el espectador de ese } \\
\text { momento, reflejo de los } \\
\text { diferentes factores cul- } \\
\text { turales, sociales, políti- } \\
\text { cos, económicos, etc. en } \\
\text { el desarrollo de la } \\
\text { educación artística. }\end{array}$ & 4 & 2 & 2 & \\
\hline
\end{tabular}




\section{Cuadro N. ' 1.6. 'Yítulo de Especialización Didáctiea}

\begin{tabular}{|c|c|c|c|c|c|}
\hline \multirow[t]{2}{*}{ Denominación } & \multirow[t]{2}{*}{ Plan de estudios } & \multicolumn{3}{|c|}{ Créditos anuales } & \multirow{2}{*}{$\begin{array}{l}\text { Vinculación } \\
\text { áreas de } \\
\text { conocimientc }\end{array}$} \\
\hline & & Totales & Teóricos & Prácticos & \\
\hline $\begin{array}{l}\text { C.1. Materias } \\
\text { Complemen- } \\
\text { tarias: } \\
\text { (Aplicadas en } \\
\text { cada caso a las } \\
\text { diferentes es- } \\
\text { pecialidades } \\
\text { propias de los } \\
\text { estudios de } \\
\text { Artes Plásticas } \\
\text { y Diseño) }\end{array}$ & $\begin{array}{l}\text { Asignaturas de Ar- } \\
\text { tes Plásticas y Dise- } \\
\text { no: } \\
\text {-Dibujo Artístico apli- } \\
\text { cado a cada una de las } \\
\text { especialidades. } \\
\text {-Dibujo Técnico aplica- } \\
\text { do a las diferentes es- } \\
\text { pecialidades. } \\
\text {-Proyectos de Diseño } \\
\text { aplicado a las diferentes } \\
\text { especialidades. } \\
\text {-El Diseño por ordena- } \\
\text { dor aplicado a las dife- } \\
\text { rentes especialidades. } \\
\text {-Historia del Arte pro- } \\
\text { pia de cada especiali- } \\
\text { dad. } \\
\text {-Talleres específicos de } \\
\text { las diferentes especiali- } \\
\text { dades. } \\
\text {-Restauración de bienes } \\
\text { culturales. } \\
\text { El currículo de las asig- } \\
\text { naturas y sus campos } \\
\text { científicos: aspectos. }\end{array}$ & 4 & 2 & 2 & \\
\hline
\end{tabular}




\section{Cuadro N. " 1.7. 'Título de Especialización Didáctica}

\begin{tabular}{|c|c|c|c|c|c|}
\hline \multirow[t]{2}{*}{ Denominación } & \multirow[t]{2}{*}{ Plan de estudios } & \multicolumn{3}{|c|}{ Créditos anuales } & \multirow{2}{*}{$\begin{array}{l}\text { Vinculación a } \\
\text { áreas de } \\
\text { conocimiento }\end{array}$} \\
\hline & & Totales & Teóricos & Prácticos & \\
\hline $\begin{array}{l}\text { C.2. Materias } \\
\text { Optativas }\end{array}$ & $\begin{array}{l}\text { Materias optativas } \\
\text { de Artes Plásticas Y } \\
\text { Diseño: } \\
\text {-Marketing. } \\
\text {-Embalajes. } \\
\text { - Realización de maque- } \\
\text { tas para los proyectos. } \\
\text { El currículo de las asig- } \\
\text { naturas y sus campos } \\
\text { científicos: aspectos } \\
\text { conceptuales y prácti- } \\
\text { cos para su elaboración } \\
\text { y aplicación a situacio- } \\
\text { nes de aprendizaje: La } \\
\text { evaluación. } \\
\text { Diseño de unidades } \\
\text { didácticas }\end{array}$ & 4 & 2 & 2 & \\
\hline
\end{tabular}

Esta propuesta estaba basada en una normativa que, como hemos comentado anteriormente, ha quedado en suspenso. Lógicamente, las nuevas propuestas deberán adaptarse a las nuevas directrices que marque el Ministerio. Sin embargo, creemos que en sus aspectos generales estos planteamientos siguen siendo válidos, y que en la próxima reforma deberían ser tenidos en consideración. En este sentido, la configuración del TED como un título de Postgrado, como parece que apunta dicha reforma, supondría que estas expectativas, tantas veces aplazadas, podrán verse realizadas en beneficio de la educación artística de nuestros futuros estudiantes.

\section{OBSERVACIÓN:}

El Anexo 1.A establecía como Área de Especialización Didáctica en Artes Plásticas y Diseño el área 18, que especificaba: "coincidente con el Área 4". Sin embargo, hay que aclarar que el Área 4 se refiere a: "Educación Plástica. Dibujo Artístico, Dibujo Técnico, Fundamentos de Diseño, Imagen, Técnicas de Expresión Gráfico-Plástica y Volumen”. Dichas materias son las que se imparten en Bachillerato Artístico (nivel 2 de la Unión Europea), mientras que los Dibujos, Diseños, etc., propios de los planes de estudio de Artes Plásticas y Diseño, pertenecen en su mayoría al nivel 3 y 4 de la Unión Europea, y son siempre específicos de cada modalidad. 


\section{BIBLIOGRAFÍA}

BEYER, L. y LISTON, D. (2000). El curriculum en conflicto. Madrid: Akal.

CALAF, R., NAVARRO, A. y SAMANIEGO, J. (2000). Ver $y$ comprender el arte del siglo $X X$. Madrid: Síntesis.

COROMINAS, A. (1994). La comunicación audiovisual y su integración en el curriculum. Barcelona: Graó.

EISNER, E. (1992). La incomprendida función de las artes en el desarrollo humano. Revista Española de Pedagogía. $\mathrm{N}^{\circ}$ 191.pp.15-33.

------ (1995). Educar la visión artística. Barcelona: Paidós.

FERNANDEZ, F. Y MARTINEZ, J. (2000). Manual básico de lenguaje y narrativa audiovisual. Barcelona: Paidós.
GARDNER, H. (1994). Educación artística y desarrollo humano. Barcelona: Paidós.

GRAEME CHALMERS, F. (2003). Arte, Educación y Diversidad cultural. Barcelona: Paidós.

LAZOTTI, L. (1994). Educación Plástica y Visual. Madrid: MEC y Mare Nostrum.

MACEDA, P. (1994). La educación ante los grandes cambios culturales. Madrid: Euroliceo.

MIRZOEFF, N. (2003). Una introducción a la cultura visual. Barcelona: Paidós.

PARSONS, M.J.(2003). Cómo entendemos el Arte. Barcelona: Paidós.

TRAFI, L. (1999). Construir miradas desde la historia social del arte. Guías Praxis para el profesorado. Plástica y Visual. Barcelona: CISS-PRAXIS.

\section{RESUMEN}

El artículo aborda el tema de la Formación del Profesorado de Educación Artística en la enseñanza secundaria, centrándose en la reforma del Curso de Aptitud Pedagógica (CAP), y con una propuesta para el Título de Especialización Didáctica (TED) previsto en dicha reforma.

Palabras clave: educación artística, enseñanza secundaria, formación del profesorado, reforma educativa.

\section{ABSTRACT}

This article takes over the subjet of the teachers training in the field of Artistic Education at the Secondary Schools, advances the reforms in the Course of 
Pedagogic Aptitude (CPA), and a proposal for the Tittle of Didactic Specialitation (TDS) observed in such a amenament.

Key words: artistic education, secondary school, teacher training, educational reforms. 